\title{
Application of Etymology and Semantic Field Theory for Second Language Acquisition
}

\author{
ZHANG Jie \\ China Youth University for Political Sciences, Beijing, China
}

\begin{abstract}
Vocabulary acquisition is of fundamental importance in learning English, but little importance has been attached to how to grasp more words and how the words are better understood in senior stage of language acquisition. Usually, students are asked to memorize words. Anyway, just memorizing or learning isolated words by heart is not an effective way. So it is significant to make some researches to find effective ways of learning vocabulary. Etymology and semantic field theory can serve as useful methods by tracking down a word's history, formation, evolution, etc., and by memorizing more words from the same semantic group. This paper is to study how etymology and semantic field theory contribute to English vocabulary acquisition. Four parts of etymology are illustrated.
\end{abstract}

Keywords: etymology, semantic field theory, vocabulary acquisition

\section{Introduction}

In learning English, vocabulary is essential. How to grasp more words and understand the concept of words are important. There are many ways for English learners to learn the words by heart. However, with the help of some language theories, vocabulary learning can be easy and multiplied at the same time. Etymology is one of the useful ways, it can help learners to be familiar with more words with culture and history, expand vocabulary, reduce spelling errors, distinguish similar words, improve the ability of guessing words' meanings, and memorize long and complicated words efficiently. Semantic field functions is another theory can be used in enlarging vocabulary.

English is widely learnt in schools in China. Vocabulary acquisition is indispensable for English learning. Learners begin learning English by starting with words. A scholar once said: "Without grammar, very little can be conveyed; without vocabulary, nothing can be conveyed” (Wilkins, 1972, p. 111). Any language learner has the experience that however one's grammar is correct, however, one's speech sounds are beautiful, without proper words, the communication cannot go on. So the wide-range and in-depth of vocabulary decide one's language ability and indicate one's language accuracies and richness.

As children learn mother tongue, the first stage is one word stage, and telegraphic stage, the phrasal stage, the whole sentence, and lastly the pragmatic application. Both mother tongue and second language learning need large vocabulary. Especially in the second language learning, vocabulary is basic for the grasp of the target language. But vocabulary acquisition has not been attached much importance compared with the grammar learning in China. After the first few years of learning English, the greatest problem at senior stage is how to acquire English vocabulary effectively and efficiently.

ZHANG Jie, associate professor, Foreign Language and Literature Department, China Youth University for Political Sciences. 
The second language vocabulary learning accompanies language learners throughout the learning process even after acquiring all the basic grammatical rules. Compared with grammar learning, the vocabulary acquisition of second language has been a hot issue which attracts a number of scholars' attention all over the world. Schmitt and Mcarthy (1997) had justified the importance of vocabulary in-depth acquisition, based on nation's vocabulary frame theory (1990). Domestic scholars WEN (1996) and DAI (2000) had also made great achievements in this area, and they had reached the conclusion that English learners in China have problems in vocabulary in-depth acquisition, i.e., the master of different meanings and their relationships and usage. With that conclusion, the historical analysis of vocabulary can help English learners to understand word origins better. Historical study of words is etymology. And the semantic field also helps learners to acquire more words and know the relationship with other words.

\section{Etymology Helps Learners to Be Familiar With More Words With Culture and History}

Etymology is a branch of lexicology in linguistics that investigates the origin and history of words and their meanings. According to the explanation in Oxford Advanced Learner's English-Chinese Dictionary (2002), etymology provides a diachronic point of view to study English words, which can help learners improve vocabulary in-depth acquisition.

In general, etymology is the study of origin and history of words and their meanings, and this paper mainly studies etymology in its broad sense, which is according to the chief editor Ilson (1983) of Longman Dictionary of Contemporary English, is the information on the formation of words, phrases, and terms. He had classified the etymological information in a broad way, covering four parts: (1) original words and cognates; (2) morphological analysis of word structure; (3) morphological analysis of word formation; and (4) cognitive analysis of word formation and evolution. Different etymological parts contribute to English vocabulary learning differently. Detailed analysis with the role of these four parts extensively will illustrate.

\section{Etymon and Cognate}

Etymons and cognates help learners trace English words' origins. Etymons are original words or prime words. As to cognates, they refer to words having the same source or origin like the English word "house" and the German word "haus". And the English word "cotton" is spelt as "cotton" and "cotone" in French and in Italian respectively. Here this phenomenon will be favorable for the Indo-European speakers. For the Chinese speakers, they need to learn the basic root form in English first.

The history and evolution of a word facilitate word memorization. For instance, "gossip" derives from the Anglo-Saxons” term "godsibb”. As "sib” means "relative”, from which modern English gets "sibling”, "godsibb” denotes one’s "relative in God". In Middle English, it simply meant "close friend". It is easy to imagine how close friends always "indulge in idle talk", which was the meaning in the 16th century, and where the modern sense "idle talk" derived. In this case, by tracing back to "godsibb", learners will know how "gossip" gets its modern meaning. Another example is "cattle", deriving from the Latin word "capitalis" which means "of head". The extended meaning of "capitalis" is "the number of heads (of cattle)", so learners will memorize the word "cattle" by tracing its origin. Since cognates share the common origins, their meanings are often similar, and obviously, these cognates also have similar forms, so learners can find it convenient to associate a word with its cognates. "Cattle" and "capital” are cognates, and "cattle" is people’s property, so "capital" should has similar meaning as "property" or "wealth". In this way, learners acquire the word "capital”, too. In this way, many 
English words are experiencing some loss of case affixes, and become de-motivated. So the senior English learners are supposed to learn some Latin or Greek root, prefixes, or suffixes to know some difficult and academic vocabulary. Table 1 is the example for roots and Table 2 is the example for prefixes or suffixes.

Table 1

Latin and Greek Roots and the English Words

\begin{tabular}{|l|l|l|}
\hline Latin or Greek roots & English words & English words with the Greek roots \\
\hline hemo- & Blood & Hemoglobin \\
\hline herb- & Plants & Herbaceous \\
\hline hydro- & Water & Hydrate \\
\hline jur/just- & Law & Jury \\
\hline -log/logue- & Word/Thought & Dialogue \\
\hline luc- & Light & Lucid \\
\hline manu- & Hand & Manual \\
\hline meter/metr & Measure & Thermometer \\
\hline neg- & No & Negate \\
\hline ocu- & Eye & Ocular \\
\hline
\end{tabular}

Note. The table is retrieved from http://wenku.baidu.com/view/053ccf80d4d8d15abe234e3b.htm.

Table 2

Latin or Greek Prefix or Suffix and the English Derivatives

\begin{tabular}{|l|l|l|}
\hline Latin or Greek prefix or suffix & English words & English derivatives \\
\hline -dom & Quality/State & Freedom \\
\hline ex- & Out & Exit \\
\hline hetero- & Different & Heterogeneous \\
\hline hypo- & Too little & Hypoactive \\
\hline -ic & Relating to & Poetic \\
\hline -ile & Quality/State & Juvenile \\
\hline
\end{tabular}

Note. The table is retrieved from http://wenku.baidu.com/view/053ccf80d4d8d15abe234e3b.htm.

Leaning etymology helps the students in senior years to know the history of words, and culture loaded with the words and the country's culture from which words were from. That is relationship of word motivation and culture.

By tracing etymons and comparing cognates, learners' interest in vocabulary will be aroused, and then learners can acquire vocabulary efficiently.

\section{Word Structure}

The etymological analysis of word structure, a crossing domain between etymology and morphology, contributes to vocabulary in-depth acquisition and also will enlarge learners' vocabulary. For example, "flatulent”, “conflation”, “deflation”, “inflation”, and "reflation” all include the "flat”. In morphology, "flat” is a root, which is a type of morpheme and the base form of a word. And from an etymological view, "flat" derives from the Latin word "flare", which equals "blow". So the morphological role and etymological meaning of "flat" confine these words to meanings related to "blow", such as "inflate" means "to fill with air". Another example is the root: onom, onym, mean "name" with the words "synonym, antonym, and anonymous". In modern English, there are many this kind of words, so when the English learners learn this kind of words in group, they will save more time and know the meaning more clearly. 
Another equally aspect is that an etymological analysis of word structure can avoid ambiguities and guarantee the accuracy of learners' vocabulary acquisition. A good case in point is "adulterate" and "adultery", which learners are likely to relate with "adult", for most learners have already acquired the common word "adult" at the primary learning stage. Actually, neither of them has any connection with "adult". When it comes to the two words" structures, they both have the morpheme "ulter", which means "other", in etymological sense. So the two should be related with "other", which is how "adulterate" gets the meaning "to add other substances" and "adultery" gets its "sleep with other people instead of his or her spouse".

As been noted, the etymological knowledge of word structure is indispensable. Tracing etymological information of English words' roots, affixes, stems, and other morphemes, learners are able to increase the effectiveness and precision of vocabulary learning, and will be more interested in the word's history.

\section{Word Formation}

Word formation refers to the process of how a word is formed. With morphological knowledge of word formation, learners can easily get a word's meaning even when they simply know a part of it. The common types of word formation are the compound, blending, conversion, blending, acronyms, and backformation. By the way of word formation, learners will know even larger numbers of words.

\section{Allusions}

In the boundless and expansive sea of English vocabulary, numerous words derive from biblical stories, literature, fairy tales, names of places and people, etc.. To put it in another way, a large number of English words stem from profuse allusions. Learning some allusions of English words can foster learners' interest in vocabulary and helps to consolidate and remember words. A particular example is "hamburger", which has nothing to do with ham. It originates in the German city and port of Hamburg, from where sailors or emigrants took the delicacy across the Atlantic with them to America. Then it was called a Hamburg steak or, using the German adjectival form, a Hamburger steak.

Does one can imagine that "echo" is a name of nymph? In Greek mythology, "echo", as a penalty for distracting Hera from observing Zeus' infidelities, lost all power of speech, except the ability to reply. Then the defect caused her to pine away in her unrequited love for Narcissus, until nothing but her voice remained. Tracing back to the sources of English vocabulary, one can find a great quantity of fascinating allusions, which will awaken people's zest for learning vocabulary. Consequently, allusions will intensify learners' understanding of a word's meaning and facilitate memorization of words. There are lots of culturally-loaded words, Odyssey, quixotic, philippic, fustian, Frankenstein, Ishmael, Bubble, and Babbitt, just mentioned a few.

\section{Significance of Learning Etymology}

As has been discussed above, each part of etymology is conductive to English vocabulary acquisition. So knowing some etymological knowledge in vocabulary acquisition is of vital importance and great significance.

\section{Expanding Vocabulary}

If the root "vis" (i.e., see) has been acquired, then words containing it can be acquired easily, such as "visible”, "invisible”, "visit”, "revise”, and so on. More examples are the suffix with academic meaning: (1) -grapy, stands for "science and writing”: biography, calligraphy, and geography; (2) -ic, ics, stand for "science": logic, mechanics, optics, and electronics; (3) -ology, stands for "science": biology, zoology, and technology; (4) -nomy, stands for "science and art”: astronomy, economy, and bionomy; (5) -ery, stands for 
"science and technology": chemistry, cookery, and machinery; and (6) -y, stands for "science and art and method”: photography, philosophy.

\section{Reducing Spelling Errors and Distinguishing Similar Words}

It is reported that a number of spelling errors, especially the ones between similar words are due to the lack of adequate etymological knowledge. Many learners cannot distinguish between "proceed" and "precede", but when they know their roots and affixes; the difference would be made clear. Actually, the two words share a same root "cede", meaning "to go", and "ceed" is only a variation of "cede" in "proceed". But they have different prefixes: in "proceed", "pro" means "for" or "towards", while "pre” in "precede" refers to "before". So equipped with etymological knowledge of words, one can distinguish similar words and thus reduce spelling errors.

With more knowledge about the origin of words, students especially seniors are clear about the formation of words. That may avoid the misspelling of the words. For example, in English, words are like "altitude" and "altruism" are words with alt- means "high" and -itude means the word is a noun. And the altru- means "other". So with the knowing of alt- and altru-, learners easily remember the spelling. So are the ambi- and dextr are helpful to reduce the spelling errors with the words like "ambidextrous"-be skillful or versatile with two hands. And there will be easier to remember the words like: ambience, ambiguous, ambivalent, etc.

\section{Improving the Ability of Guessing Words Meanings}

In the process of reading, it is unnecessary and impossible to recognize every word and know their meanings. One can guess the new word's meaning immediately rather than look it up in the dictionary, so guessing is an important ability in reading. And guessing is mainly based on one's schematic knowledge, including knowledge of background, culture, setting, and most importantly, the knowledge about the words. If one knows that "bio" means "life", one can guess "biology" is a scientific study of the life and structure of plants and animals. As to the word "apolune", which means the point of an orbit around the moon farthest from the moon's center, one can guess its meaning from the meanings of "apo" (away from) and "lune” (moon). So learning etymology will improve one’s guessing ability of words' meanings.

\section{Memorizing Long and Complicated Words Efficiently}

English learners always find long and complicated words notoriously difficult to remember, which however, may become easy to memorize after knowing their etymological information. For example, Middle English: from Old French pome grenate, from pome "apple" + grenate "pomegranate” (from Latin (malum) granatum “(apple) having many seeds”, from granum “seed”).

\section{Semantic Field Functions in Enlarging Vocabulary}

Beside the etymological way for enlarging vocabulary the semantic field is another way for the seniors to learn more words. By Longman Dictionary of language Teaching and Applied Linguistics (2000), semantic field is the organization of related words and expressions into a system which shows their relationship to one another. The theory of semantic field helps the students review and associate the words related. For example, animal is a semantic field, and in it there are many words concerned with the names of the animals. And in a semantic field, each hyponym can be a superordinate and has its hyponyms. The understanding of the semantic system helps the learner to be clear about the relation of the words and easy to learn and memorize and use the words. As for the semantic field, there are groups of words with semantic synonyms, which are the 
semantically synonymous field and groups of words with semantic antonyms, which are the semantically antonymous field. For example, in the semantic field for color, there are the words: red, yellow, blue, black, purple, and orange; the semantically synonymous field are: laugh, smile, grin, giggle, roar, guffaw, mock, jeer, and beam; and the semantically antonymous field are: accept/refuse, buy/sell, easy/difficult, and true/false.

There are numerous semantic fields in English. The greatest numbers are the synonymous semantic field. Here are some more examples given in Malllery's How to Enlarge and Improve Your Vocabulary (1994) cited in LU in his Modern English Lexicology (1983):

Admit: own, concede, confess, acknowledge;

Artificial: unnatural, affected, false, counterfeit, spurious;

Awkward: clumsy, ungainly, ungraceful, unskillful, embarrassing, disconcerting;

Brief: short, succinct, terse, condensed, momentary, quick, fleeing;

Discover: ascertain, determine, unearth, learn, dig up, bright to light, meet with, come upon, come across, recognize, identify, reveal, disclose. (p. 119)

With the semantic field, meanings of the words are exact and the students are clear about the position of the words in the semantic field.

Through the above analysis, the roles of four different etymological parts in learning English vocabulary have been discussed; the significance of learning etymology is illustrated from different aspects. Learning etymological information is of vital importance in English vocabulary acquisition.

The etymological aspect and the semantic field aspect are essential for the seniors to overcome the difficulty in vocabulary. A conclusion can be reached that etymology and the semantic field theory play a fundamental role in English vocabulary acquisition, so they should be applied into learning vocabulary. Both teachers and students should pay attention to the etymological information and semantic field theory, and try to make a full use of them. That will help the seniors to overcome the "bottle neck" in learning English.

\section{Conclusions}

With the analysis and examples given, it is obvious that the etymology and semantic theory really play a reliable, explicit, and practical role in the vocabulary learning. Therefore, the etymology and semantic field provide the useful ways for learners to have a deeper understanding for vocabulary and the language. Both the teachers and the students should carefully apply the methods into the second language learning.

\section{References}

DAI, M. C. (2000). Study on the vocabulary of the second language. Beijing: Foreign Language Teaching and Research Press. Hornby, A. S., Wehmeier, S., \& Ashby, M. (2009). Oxford advanced learner's English-Chinese dictionary (7th ed.). Beijing: The Commercial Press.

Ilson, R. (1983). Etymological information: Can it help our students?. ELT Journal, 37, 76-82.

K Dictionaries Ltd.. (2000). The American heritage dictionary of the English language. Boston: Houghton Mifflin Company.

LU, G. Q. (1983). Modern English lexicology (p. 119). Shanghai: Shanghai Foreign Language Education Press.

Pierson, D. H. (1989). Using etymology in the classroom. ELT Journal, 43, 57-63.

Richardson, J. C., Platt, J., \& Platt, H. (2000). Longman dictionary of language teaching and applied linguistics (p. 264). Beijing: Foreign Language Teaching and Research Press.

Schmitt, N., \& Mcarthy, M. (1997). Vocabulary: Description, acquisition and pedagogy. Cambridge: Cambridge University Press. WEN, Q. F. (1996). Strategy of English learning. Shanghai: Shanghai Foreign Language Education Press.

Wilkins, D. A. (1972). Linguistics in language teaching. Cambridge, M.A.: MIT Press. 